\title{
Unravelling Cultural Dynamics in a European Privatized State Enterprise
}

\author{
Marcel Veenswijk, Alfons van Marrewijk
}

Department of Organizational Sciences, VU University Amsterdam, Amsterdam, Netherlands.

Email: \{m.veenswijk, a.van.marrewijk\}@fsw.vu.nl

Received December $3^{\text {rd }}, 2011$; revised January $16^{\text {th }}$, 2012; accepted January $29^{\text {th }}, 2012$

\begin{abstract}
In this paper, based on a case study regarding the institutional privatization of a former French public sector ferry liner, new concepts in cross-cultural research are developed and explored. We argue that the ability to influence the direction of the change process of the ferry liner organization, called "Pascal Paoli", heavily depends on the way actors are able to insert their so-called "narratives of change" into the power arena by means of a specific group of organizational "editors". After a short introduction to the case, we identify four basic anthropological concepts which lead in understanding and analysing the case. The paper concludes with a reflection on the usefulness of the central concepts.
\end{abstract}

Keywords: Cross-Cultural Management; Narratives of Change; Intervention; Privatization; Change Dynamics

\section{Introduction}

Cross-cultural cooperation has become an important topic in the management of complex organizational networks [1]. Increasingly, employees of different cultural backgrounds work together in large-scale international science projects, strategic alliances, mega-projects, and outsourcing activities [2]. Cultural differences are held responsible for the failure of successful cooperation. According to Holden [3] similarities in national and corporate cultures are associated with successful cooperation. Jabob [4] indicates that the sources of tension and the dynamics of instability vary with the national culture of the firms. It is now widely recognized that the organizational and national cultures of alliance partners influence the success of international projects and collaborations [5].

In the past, the discussion on cross-cultural management has been dominated by authors such as Hofstede [6] and Trompenaars [7]. Their basic argument is that national cultures can be measured and typified by means of a set of predefined dimensions, such as power distance, masculinity, temporality and uncertainty. The national scores on these indicators define the "fit" between the organizational dynamics and the national culture in which these organizations operate. This multi dimensional perspective has received criticism for its singular focus on nation-state cultures and for the absence of power issues, ambiguity and situational behaviour Distinguishing value dimensions and the quantification of these dimensions with indexes have stimulated the assumption that cultural differences are stable, measurable and universal within a given country. To perceive organizations and nation-states as homogeneous entities is out of touch with daily practices in a globalizing world [8]. Dimension models assume cultural differences to be expressed in a stable and quantified distance between two national cultures. Furthermore, the dimension models have generated the assumption that cultural differences are determined by national cultural differences and can be overcome.

New directions in cross-cultural research are being explored. Jackson and Aycan [9] focus on how particular practices work in a given cultural context. Soderberg and Holden [10] propose a social constructionist approach to studying the management of multiple cultures. In this socalled "anthropological perspective", differences, as much as any other forms of organizing within a multiple context of socially interdependent networks, are considered to be the object and outcome of social interactions. If we adopt the view that organizations are networks of competing narratives, organizational change inherently involves a struggle as to meaning. Consequently, organizational and cultural change processes will be manifested in multiple narratives and counter narratives, through which actors attempt to legitimize the frame of reference that best serves their interests in each particular situation [11].

In this paper we present a case study in which national and organizational cultures are "blurring" in a complex 
process of organizational change. We focus on "Pascal Paoli", which is one of the ten ferry lines of the French Societe National Corse Mediterranee (SNCM). In 2005, SNCM was to be privatized by the French government, but heavy protests from French as well as key (political) Corsican actors blocked this plan. During the change process, increasingly, SNCM became an arena for revitalizing cultural groups, resulting in a tragic incident on the Pacsal Paoli.

In this case, the groups developed their own stories regarding the privatization and reframed new events in terms of their own cultural framework. Based on this case, we develop four theoretical concepts in order to contribute to a better understanding of the cultural dynamics in complex change processes.

\section{Introduction to the Case}

On 28 September 2005, the CNN news programme opened with surreal images of the Pascal Paoli, the 180metre long ship of the French state enterprise SNCM. More than fifty French commandos, dressed in combat gear and wearing balaclava helmets, used five Super Puma helicopters to force their way on board the ferry. Within a short space of time, they managed to overpower the forty-strong crew, to take over the ship and imprison the dazed employees in a closed-off area. The ship set course for Marseilles, the industrial port it had left earlier that day.

Below the expressive heading "La SNCM ou l'imaginaire Corse", Le Monde gave an account of this event. The newspaper reported that the action taken against the Corsican agitators had been a success. Paris had made it clear that the primacy of the French state government lay indisputably in Paris, certainly not with the islands, which, after all, could scarcely support themselves economically [12].

The Pascal Paoli is one of ten ships of the SNCM line which has been providing the connection between the French mainland and the island of Corsica for decades. From the port of Bastia, together with the Italian competitor Corsica Ferries, it acts, as the lifeline of the Corsican economy.

In the 1990s the French government put the SNCM ferry service, along with countless other state enterprises, on the list of organizations nominated to be privatized. Economic analyses by the Ministry of the Interior pointed out that, over the last ten years, the ferry company had suffered losses between one hundred and one hundred and fifty million euros, and that it could no longer be subsidized [13]. The organization was said to be characterized by an inwardly focused, customer-unfriendly orientation, and groups of Corsican employees (often appointed on the basis of family ties) aboard the ships were said to have been resisting for generations, in a militant manner, anything aimed at change and innovation. KPMG International, the consultancy firm charged with auditing the organization, concluded that the SNCM ferry service would only be viable if it were rapidly transformed into a decisive organization with a service culture.

Privatization of SNCM is taking place by means of that which is referred to as a private investment formula: a commercial party, Butler Capital Partner Investment, is prepared to take over the entire fleet for the sum of thirtyfive million euros, approximately ten per cent of the actual value of the ships in question. The consequences of the privatization are obvious, however: approximately three hundred of the twenty-four hundred employees are to be laid off, while the fear of that which is referred to as "the dictatorship of the shareholder" is giving rise to fierce resistance, particularly on the part of the nationalistically-oriented Corsican trade union Syndicat des Travailleurs Corses (STC).

In the first instance, the occupation of the Pascal Paoli appears to have been a traditional French method of resolving conflicts. The love of grève (striking) touches the French public identity, whereby the brotherhood is called upon to guarantee collective freedom. However, with his pronouncement: "We are taking the ship, a production unit of the Corsican people, back to its homeland", trade union leader Alain Mosconi pointed out that the action betrayed a deeper dimension. Corsican nationalistic sentiments form the basis of the struggle to keep the Corsicans from becoming the plaything of a commercial entrepreneur [14].

The action taken by the French government appeals to an image, held by many, of the concept of intervention: that of a visible, power-related form of intervention by an actor who imposes his will on one or more oppositional parties. There is a sense of urgency, a clear symbolic value, and the intervention takes place within a clearly defined timetable. Moreover, the outcome has been clearly defined beforehand.

In this case study, a state organization utilized a brutal display of power against its own employees; employees who are part of an ethnic-national network and who use the organization as a political arena, with the aim of realizing their own cultural dominance. As such, the intervention degenerated into a means of influencing a culture which goes well beyond SNCM's internal industrial organization.

In comparison to other European case studies on privatization, the intervention sketched above appears to be unprecedented. We did, however, come across a number of other new noticeable thematic concepts for the study of cross-cultural dynamics. To begin with, in almost all the cases we studied, cultural change was legitimized by one or more alternatives, partially competitive narratives, 
resulting from a socially constructed sense of urgency. In the case of SNCM, these so-called "narratives of change" did not only concern the modernization of the French public administration and the much called for privatization but, above all, the revolt against the French state and its residents. We came across these narratives in the reactions of the parties involved. These parties organized themselves along the lines of various sub-identities, whereby actors presented themselves-depending on the situation-as Corsicans, seamen or SNCM employees respectively.

Secondly, every day dynamics transform these narratives into so-called "micro stories", which sometimes unfold in line with the main story, but sometimes at a (greater or lesser) tangent, as a counter-narrative. Elements such as "gossiping", "whispering" and "small talk" are included in these micro stories.

Thirdly, there is the theme of classification. Some narratives have a considerable impact and appear to reproduce themselves for ever, while other narratives dissolve into meaningless pools of timid waves. Apparently, specific story rankings develop in the course of cultural processes through that which we call "windows of meaning”. These windows of meaning are typical of the way narrative impacts, directly or indirectly, on the organizational members [15].

Finally, there is the matter of "editing", the process by which narratives are brought into line with one another and - usually by an external "editor"-made to fit. Editing takes shape via a large variety of interventions, which in turn are connected with the underlying values and basic assumptions of the organizational configurations involved [16].

For us, the four themes: 1) narratives of change, 2) micro stories, 3) windows of meaning and 4) editing, form a rough guideline for analysing and understanding the processes of cross-cultural cooperation in complex organizational networks. In the next section, these concepts will be discussed in more depth, relating to the case of the Pascal Paoli.

\section{Theorizing the Core Concepts}

\subsection{Narratives of Change}

Foucaultian analyses have taught us that so-called grand narratives have an undeniably disciplinary effect on the manner in which everyday realities are unlocked [17]. Narratives of change may be regarded as types of great stories. Brown defined these narratives as regimes of truth, meta-stories to which other stories are made subservient [18].

We come across narratives of change at all levels of reality: in the layout of buildings, the use of space and time, and the artefacts and symbols which have been used. A visit to the new Dutch ING Bank House makes the visitor thoroughly aware of the story of transparency, professionalism, global success and sense of commerce. Everyone who enters the building should relate to this story in one way or another; by denying it, conforming to it or resisting it, in much the same way that the layout, symbols and smells of an average hospital stimulate visitors to ponder potential disorders and the importance of medical knowledge and to respect the medical profession.

The privatization of the Pascal Paoli fits in with the comprehensive narrative of change which, over the past few years, has taken shape around the administrative reform of the European public administration. The story of new public management is dominant in virtually every country in Europe: a neo-liberal ideal image of organizational culture: the future perfect [19]. Everywhere we look we see similar concepts and language codes concerning small, efficient and flexible governments, the more market-oriented executive services which focus on the development of maximum customer-friendliness, as well as the professional civil servant who is the endless object of digital upgrading by means of e-learning and e-governance. Why? For, to some extent, the top politicoadministrative echelon actually believes in this course and, furthermore, has committed itself to the story of the market and, to a greater extent, these concepts have come to determine the frameworks whereby opinions have been given-politico-administratively speaking-a recognizable, acceptable and, thus, legitimate character.

Apart from the content-driven stories, we can discern the process-oriented narratives of change: stories about the process by means of which the cultural ideal image can be attained. Meanwhile, for those of you who have become lost, stories from everyday practice about the manipulation of culture form an unmistakable part of organizational scientific analyses of this theme, since these stories represent the views of the actors involved, which have immediate repercussions for organizational practice.

We will name the two stories which have the greatest contrast: the story of the planned cultural transformation, implicitly adhered to by the French national government in the case of SNCM versus the story of cultural selfdevelopment and self-actualization, snippets of which can be discerned in the accounts of the STC trade union. Both stories have their own logic, concepts and benchmarks for success.

Over the past few years, the story of cultural development has been increasingly absorbed into the practices of complex organizations [20]. This can be explained to an important degree not only by the "fit" with current images of the time, whereby individualization, participation and democratization have become increasingly important, 
but also by the rise in the lucrative "market" of consultancy firms, coaches and trainers, who have further developed and commercialized this story.

However, the processes of cultural change are not only regulated by the narratives of change. It is precisely the micro stories, ensuing there from, which add colour to the way in which cultural change processes unfold in everyday practice. These "local" micro stories are unpredictable, not composed, characterized by a lack of consistency and are replete with paradoxical ingredients [21].

\subsection{Micro Stories}

In the case of the Pascal Paoli, the story of the privatization differentiated into several micro stories. A first narrative unfolded around the credibility of the key actors involved. The day after the helicopter intervention, Le Monde opened with an important news item. One of the catering employees recognized De Villepin's FrenchAmerican guest, Walter Butler, as the owner of Butler Capital Investments - the man with whom the Prime Minister had been spending time, with great regularity and on very friendly terms, in one of the ferry's lounge areas during the last two years. Their alleged friendly relationship swiftly crystallized into the story of a underhand deal, a story of wheels within wheels. Julien Dray, the CTG foreman, expressed it as follows on BBC News: "Behind this spectacular police operation there lies above all the despair of the workers who have been pushed to the limits by a government bent on selling off a public service at a knockdown price to one of its friends" [22]. The following day, the Prime Minister responded with an interview for TV France, in which he publicly declared that he was not conducting any direct negotiations with Butler. By that time, the story had already been picked up by practically every large foreign news station.

The second story which unfolded was that of the unreliable, "power-hungry" unions. According to a group of director Bruno Vergobbi's staff members, the Confereration General du Travail, (CGT), in particular, is said for years on end to have caused death and destruction among the SNCM employees and prevented important, necessary reorganizations through intimidation. Moreover, the CGT leader, Mosconi, is said to have aspired to an executive position within the SNCM organization, becoming firmer in his resistance after he had been turned down [23]. The third story we will mention here is of course that of the injustice suffered by the ordinary man: the man on the "shop floor" who sacrificed himself as a sailor. In the union journal, Le Militant, one of these sailors, Marc Kinzel, explained that his act had only been intended to express his displeasure about the knife which had been held to his throat. Privatization was equated with unemployment, unemployment with poverty, illness and, ultimately, the begging bowl for him and his family. According to him, the way he had been treated in a French cell had been hell, no less than an act of French colonial aggression against the little man from poor, disadvantaged Corsica. Kinzel defined himself as a man who could only survive through group solidarity and proclaimed himself to be a man "just like any other" [24].

The micro stories embody the tensions and contrasts to which the actors have to relate in their complex reality. In the story of SNCM, this naturally concerns not only the constant tension between the collective vs the individual, the central vs the local, but also the tension among the here and now, the uncertain future and the illustrious past. Some micro stories are purposely created to refute or completely destroy the main story, as in the first two examples. We often see that things are mixed up in various ways, the micro stories eventually becoming entwined and hybridized with one or more elaborations of the main story [25]. The question as to why some stories preserve their authenticity, are successfully reproduced and materialize, while others constantly change or quietly fade away during the change process, has everything to do with "windows of meaning". We will go into this in greater detail in the next section.

\subsection{Windows of Meaning}

There are several factors which play a role in the influence which stories have: the power of their narrative, the extent to which the logic of their narrative is open to change, the manner in which the stories are told, the technology by means of which the stories can be spread and, last but not least, their aesthetic value [26]. When the problem of story classification is reduced to the dimensions directed towards reproduction, that is recognition and modification, we arrive at a diagram (Figure 1) containing four types of story scripts: 1) blind scripts, 2) dynamic scripts, 3) transformative scripts and 4) direct scripts.

Blind scripts, which can also be described as "duds", appear during various stages of cultural change processes. Duds linger on the "backstage" and do not become part of the interaction arena. At times, these stories are not in the least recognized by the actors to which they pertain, since, for example, there is no connection with the used terminology and symbols. We call them "closed narratives". Blind scripts can be placed opposite direct scripts: stories which are largely adopted as they were. We often come across direct scripts in situations in which media actors play an important role: press releases are literally copied by television, news programmes and newspapers, after which they are adopted by an organization's members. In the case of the Pascal Paoli, our students counted the phrase "The workers were made to kneel while other 


\begin{tabular}{|c|c|}
\hline $\begin{array}{l}\text { Blind Scripts } \\
\text { No recognition/no } \\
\text { modification } \\
\text { * backstage dominance } \\
\text { * lack of interaction } \\
\text { * closed narratives }\end{array}$ & $\begin{array}{l}\text { Dynamic Scripts } \\
\text { Recognition/modification } \\
\text { * front- and backstage } \\
\text { * multiple interaction } \\
\text { * open narratives }\end{array}$ \\
\hline $\begin{array}{l}\text { Transformative Scripts } \\
\text { No recognition/modification } \\
\text { * front- and backstage } \\
\text { * multiple interaction } \\
\text { * open narratives }\end{array}$ & $\begin{array}{l}\text { Direct Scripts } \\
\text { Recognition/no modification } \\
\text { * front stage dominance } \\
\text { * linear interaction } \\
\text { * closed narratives }\end{array}$ \\
\hline
\end{tabular}

Figure 1. Windows of meaning.

officers handcuffed their leaders” 617 times.

Both dynamic and transformative scripts pertain to the modification of original narratives in new realities or perspectives. In the case of SNCM, Sarkozy, the Minister of the Interior, redefined the seamen's heroic strike as a criminal act carrying a prison term of twenty years. The sailors are regarded as criminals, enemies of the state, who should be locked up and put on trial.

In retrospect, windows of meaning can be used to answer the question as to why certain narratives make it into the arena of cultural change while others do not. Over the past few years, the focus of interest of culture researchers has been directed at the various aspects of the reproduction of cultural narratives. In the process, their attention has been shifting more and more towards the factors and interventions regulating the "fit" of stories. This so-called editing is the last concept of the analytical model.

\subsection{Editing}

In the case of editing, the spectrum shifts from the story to the actor. Editing is based on the notion that there is an editor who, in the capacity of a third actor, plays an intervening role as a "stylist", "translator" or "broker" of stories. According to Richard Rorty, editing can be traced back to the epistemological basis of social interaction. In his view, definitions in terms of a group's cultural, social and ethnic superiority can result in a fixation and "dead-lock" between (groups of) actors. The exchange of ideas, the "travels of ideas", grinds to a halt at a certain point in time, resulting in social fixation [27].

Sometimes, editing follows naturally from a management question: the manager senses a gap with the shop floor, feels as though messages are not getting across or, in the case of change initiatives about which he himself is very enthusiastic, striking a chord. The editor, for example in the capacity of a (communications) consultant or trusted representative, edits the messages as much as possible in the presumed language of the employees. We also come across editing in countless other places in change processes where there is a lack of fit between stories, and during which social fixation takes place. In such cases, the editor may act, for example, as a cultural broker, and as the catalyst for change.

Cultural brokers have traditionally been an important object of study for anthropologists. This sometimes concerns actors who have several cultural/ethnic characteristics and, thus, are able to bring groups together. It is obvious that the market of commercial consultancy firms is a market of cultural brokers. It is striking that SNCM did not work with editors who had been explicitly appointed. However, during the various stages of the change process, we have seen several key figures actively focused on the redefinition and modification of the narratives by means of the micro stories.

Research on social fixation has, meanwhile, received a great deal of attention in intervention literature. It has emerged from these studies that, in organizational practice, actors not only find it difficult to make their own "theories in use" explicit, but also to reflect thereupon in an active manner, and raise basic views (basic beliefs) for discussion within the context of a change process.

Over the past few years, countless studies have been conducted on the processes of becoming aware of organizational culture and "third-party" interventions, for example by means of biographical analysis, coaching and counselling T-group training, and inter-group consultation. Within this context, research on social fixation is increasingly focused on the direct relationships between actors and narratives, in particular the ways in which editors can use such narrative elements as metaphors, figures of speech and analogies to enlarge the capacity for reflection and, thus, the level of support for the change process.

As a cultural intervention, editing is not only manifest at an individual level by editors, but also on a collective level by means of so-called "communities of practice" [28]. Communities of practice (CoPs) usually concern multidisciplinary groups of initiators which organize themselves around a specific narrative construction: for example, by elaborating such themes as service provision and integrity. The key element is the migration of the discursive practices (travels of ideas) by a group of actors which is rooted (in the shape of knowledge, expertise, cultural baggage) in several organizational domains.

Editing assumes that the "third actor" is capable of projecting himself into several alternative (partially competitive) realities. According to Richard Rorty, this presumes an ironic perspective: "I call people of this sort ironists because their realization that anything can be made to look good or bad by being redescribed, and their renunciation of the attempts to formulate criteria of choice between final vocabularies, put them in the position which Sartre called 'meta stable': never quite able to take 
themselves seriously because always aware that the terms in which they describe themselves are subject to change” [27].

\section{Conclusions}

In this paper we have explored new directions of crosscultural management. The focus of such research is no longer exclusively on national cultural differences, but includes power, multiple cultures, sense making and narratives. In the case of the Pascal Paoli, we made a connection between individual actors, the organizational context and organizational strategies. Cultural diversity could be observed at different levels; the French government, SNCM management, the Corsican sailors, army marines, professional seamen and SNCM employees.

This is where the multi-dimensional models are not much use in understanding the dynamics of cultural cooperation in organizational networks. The over-simplified and static perspective of French culture in Hofstede and Trompenaars' multi-dimensional models give no space for the regional culture of Corsica. We do not learn about the strong identification of Corsicans with their island and the nationalistic historical tensions of Corsica and mainland France. Furthermore, power issues and the situational use of cultural differences, so important in the case of the Pascal Paoli, are absent in these multi-dimensional models.

The management of the multiple culture approach has been much more helpful in studying the case. Cultural diversity is perceived at multiple levels and related to issues of power, the social construction of cultural differences and narratives. In such an approach, stories about the "other", jokes and stereotyping play an important role.

In the case of the Pascal Paoli, the French state organization, SNCM, has used an ethnocentric strategy to deal with cultural differences in their organization. This domination strategy, displayed with power, is embedded in a narrative of change focused on the privatization of SNCM. This is foremost a mainland, French governmental narrative, strongly influenced by the administrative reform of the European public administration. Some authors use the term "management by machine gun" to point out the drastic change methodology [29]. This domination strategy triggers the sensitive historical relation between Corsica and France.

At the individual level, sailors at SNCM, Corsican employees rooted in ethnic-national networks, used a strategy of cultural resistance. National Corsican identity and regional cultural differences between France and Corsica constitute a symbolic resource for resistance [30]). The perceived domination of SNCM and ethnic tension triggered the offspring of an ethnization strategy of resistance [31]. The Corsican seamen created a narrative of resistance which emphasized their national identity and that of the Pascal Paoli. The ethnization strategy resulted in including the ship as part of the national cultural heritage of the island of Corsica. The ethnization strategy is supported with micro stories such as that about sailor Marc Kinzel in the union journal, Le Militant. It is precisely the micro stories which give a rich insight into the everyday practice of managing the change process of SNCM in a multiple culture context. The micro stories embody the tensions and contrasts to which the actors have to relate in their complex reality.

The dynamics of cross-cultural cooperation can be understood through the windows of meaning. The editing of the Corsican seamen in defining the Pascal Paoli as a part of their cultural identity helped to put their narrative in the French political and public arena. When the French government redefined the seamen's heroic strike as a criminal act carrying a prison term of twenty years, they regained control. The case has shown that cultural differences are not stable and universal within a given country but differ regionally. As cultural differences are socially constructed in narratives and edited they can be used strategically.

\section{REFERENCES}

[1] G. Dafoulas and L. Macaulay, "Investigating Cultural Differences in Virtual Software Teams," The Electronical Journal on Information Systems in Developing Countries, Vol 4, No. 7, 2001, pp. 1-14.

[2] B. Shore and B. J. Cross, "Exploring the Role of National Culture in the Management of Large-Scale International Science Projects,” International Journal of Project Management, Vol. 23, No. 2, 2005, pp. 55-64.

doi:10.1016/j.ijproman.2004.05.009

[3] N. Holden, "Cross-Cultural Management. A Knowledge Management Perspective,” Prentice Hall, Essex, 2002.

[4] N. Jacob, "Cross-Cultural Investigations: Emerging Concepts,” Journal of Organisational Change Management Vol. 19, No. 5, 2005, pp. 514-528. doi:10.1108/09534810510614986

[5] D. S. Staples and L. Zhao, "The Effects of Cultural Diversity in Virtual Teams versus Face-to-Face Teams,” Group Decision and Negotiation, Vol. 15, No. 4, 2006, pp. 389406. doi:10.1007/s10726-006-9042-x

[6] G. Hofstede, "Culture's Consequences: International Differences in Work-Related Values,” 2nd Edition, Sage, Thousand Oaks, London, New Dehli, 2001.

[7] F. Trompenaars, "Riding the Waves of Culture. Understanding Cultural Diversity in Business,” The Economist Books, London, 1993.

[8] A. H. van Marrewijk, M. B. Veenswijk and S. R. Clegg, "Ethnographers, Clinicians and Ethnoventionists. Organising Reflexivity in Design Oriented Change Programmes," Journal of Organizational Change Management, Vol. 23, No. 3, 2010, pp. 212-229. 
[9] A. Jackson and A. Aycan, "Editorial: From Cultural Values to Cross Cultural Interfaces," International Journal of Cross-Cultural Management, Vol. 6, No. 1, 2006, pp. 513. doi: $10.1177 / 1470595806062348$

[10] A. Soderberg and N. Holden, "Rethinking Cross Cultural Management in a Globalizing Business World," International Journal of Cross Cultural Management, Vol. 2, No. 1, 2002, pp. 103-121.

[11] D. Boje, "Narrative Methods for Organizational \& Communication Research,” Sage, London, 2001.

[12] SNCM, "Management des Organisations Terminale," STG, 2005.

[13] A. van Marrewijk and M. Veenswijk, "The Culture of Project Management. Understanding Daily Life in Complex Megaproject,” FT Prentice Hall, Essex, 2006.

[14] Le Monde, “SNCM en Greve,” 2005.

[15] M. B. Veenswijk and C. M. Chisalita, "Unraveling Power Dynamics in Communities of Practice,” In: O. R. Hernáez and E. B. Campos, Eds., Handbook of Research on Communities of Practice for Organizational Management and Networking: Methodologies for Competitive Advantage, IGI Global, Hershey, 2011, pp. 70-82. doi:10.4018/978-1-60566-802-4.ch005

[16] K. Sahlin-Andersson, "The Construction of Organizational Fields,” In: B. Charniawska and B. Joerges, Eds., Travels of Ideas, Walter de Gruyter, Berlin, New York, 1996.

[17] D. Grant, C. Hardy, C. Oswick and L. Putnam, Eds, “Organizational Discourse,” Sage, New Dehli, Thousand Oaks, 2004.

[18] B. Charniawska and B. Joerges, “Travels of Ideas,” In: B. Charniawska and G. Sevon, Translating Organizational Change, Walter de Gruyter, Berlin, New York, 1996.

[19] S. R. Clegg, M. Kornberger and T. Pitsis, "Managing and
Organizations: An Introduction to Theory and Practice," Sage, London, 2005.

[20] S. Low, "The Cultural Shadows of Cross Cultural Research: Images of Culture," Culture and Organization, Vol. 8, No. 1, 2002, pp. 21-34. doi:10.1080/14759550212105

[21] K. E. Weick, “Sensmaking in Organizations,” Sage, London, 1995.

[22] BBC News, "CTG Foreman: Pushed to the Limits," 29 September 2005, Servihoo.com

[23] E. Porsia, "Dossier Exclusif Corse: Guerre Maritime Pour la Conquête de L'île Première Partie un Gouffre Financier," 2006.

[24] Le Militant, "French 'Terror’ Troops Attack Striking Sailors Protests Erupt in Corsica," The Militant, Vol. 69, No. 40, 2005, pp. 2-3.

[25] J. Bartunek, "The Importance of Contradictions in Social Intervention,” Intervention Research, Vol. 1, No. 1, 2004, pp. 103-113.

[26] S. P. Bate, "Strategies for Cultural Change,” Butterworth Heinemann, Oxford, 1994.

[27] R. Rorty, “Contingency, Irony and Solidarity,” Cambridge University Press, Cambridge, 1990.

[28] E. Wenger, "Communities of Practice: Learning, Meaning, and Identity," Cambridge University Press, Cambridge, 1998.

[29] M. Bakhtin, “The Dialogic Imagination,” University of Texas Press, Austin, 2000.

[30] F. Barth, "Ethnic Groups and Boundaries: The Social Organisation of Cultural Difference," Allenand Unwin, London, 1969.

[31] A. van Marrewijk, "Situational Construction of DutchIndian Cultural Differences in Global IT Projects. Scandinavian,” Journal of Management, Vol. 46, No. 4, 2010, pp. 368-381. 